\title{
Scanning electron microscopy of the Graafian follicle during ovulation in the golden hamster
}

\author{
Paula B. Pendergrass and Margaret Reber* $\dagger$ \\ Department of Anatomy, School of Medicine, Wright State University, Dayton, Ohio 45435 , \\ and $\dagger$ Department of Biology, Texas Woman's University, Denton, Texas 76204, U.S.A.
}

\begin{abstract}
Summary. Ovaries from hCG-injected hamsters were examined during a timed series starting $14 \mathrm{~h}$ before and ending $4 \mathrm{~h}$ after expected ovulation. Beginning about $4 \mathrm{~h}$ before expected ovulation, large wrinkles were seen at the bases of follicles as stigma formation began. Apical surface epithelial cells were frequently found in folds bordering small areas where widely separated surface cells 'floated' on a slightly bulging underlying basal lamina. The small stigma receded, and an upright column of underlying cells formed followed by the ejection of the oocyte mass. The postovulatory rupture site was a cavernous opening in which red blood cells, tunica albuginea cells, and fibroblast-like cells were observed.
\end{abstract}

\section{Introduction}

Mammalian ovulation is a complex process which probably involves more than one of the four most frequently suggested mechanisms: enzymic digestion of the follicle wall, increased intrafollicular pressure, contraction of smooth muscle cells in the follicle wall, and inflammatory reactions. Although research continues on mechanisms of ovulation, the process is incompletely understood. One useful way to increase our understanding of follicular events is to study changes in surface morphology with the scanning electron microscope and correlate findings with underlying changes seen at the transmission electron microscope level.

Scanning electron microscope observations have been made on rabbit (Motta, Cherney \& Didio, 1971; Cherney, Motta \& Didio, 1973; Bjersing \& Cajander, 1974, 1975; Motta \& Van Blerkom, 1975; Cajander, 1976), rat (Motta \& Van Blerkom, 1975; Anderson, Lee, Le Tourneau, Albertini \& Meller, 1976), mouse (Nilsson \& Munshi, 1973; Motta \& Van Blerkom, 1975), hamster (Anderson et al., 1976) and human (Motta et al., 1971; Baccarini, 1975) ovarian follicles. However, most studies have been concerned with a detailed description of specific features of surface epithelial cells rather than with descriptions of the type presented by Motta \& Van Blerkom (1975) of progressive changes resulting in stigma formation and subsequent ovulation.

Pendergrass \& Talbot (1979) studied the ultrastructure of the thecal layers of the hamster follicle immediately before ovulation by transmission electron microscopy. The purpose of the present paper is to describe surface changes during rupture and ovulation of the hamster follicle as seen with the scanning electron microscope.

* Present address: Department of Health Services, Harvard School of Public Health, Boston, Massachusetts 02115, U.S.A. 


\section{Materials and Methods}

Female golden hamsters, aged 3-4 months, were injected with 25 i.u. hCG on Day 3 of a 4-day cycle (Day 1 was the day of finding a vaginal plug) to synchronize follicular development, with the completion of ovulation expected $14 \mathrm{~h}$ after the hCG injection. In a pilot group of 30 animals, hamsters were unilaterally ovariectomized at $0,8,12,14,16$, and $18 \mathrm{~h}$ after the hCG injection, i.e. from $14 \mathrm{~h}$ before to $4 \mathrm{~h}$ after expected ovulation, and the ovaries were processed as described below. The hamsters were then killed $18 \mathrm{~h}$ after hCG injection, and ovulation points and ova from the intact ovary were counted to verify that ovulation had occurred. In a second group of 38 hamsters similarly injected with hCG, animals were killed at $1 \mathrm{~h}$ intervals from the time of hCG injection to $18 \mathrm{~h}$ later. The observations were correlated with those from the pilot animals known to have ovulated; changes were found to be consistent between the two groups.

The ovaries were fixed in $3.5 \%$ glutaraldehyde- $2 \%$ paraformaldehyde buffered in $0.2 \mathrm{M}$ cacodylate (Karnovsky, 1965). After several buffer rinses, ovaries were post-fixed in $1 \% \mathrm{OsO}_{4}$ buffered with cacodylate. This fixation procedure was the same as that used previously for the transmission electron microscope studies (Pendergrass \& Talbot, 1979). Ovaries were dehydrated in a graded series of acetone and critical-point dried with $\mathrm{CO}_{2}$. They were coated with carbon and gold palladium in a Denton vacuum evaporator with continuous rotation. Specimens were viewed and photographed in an AMR 1200 or Philips 500 scanning electron microscope.

\section{Results}

Ovulation occurred as early as 12 or as late as $16 \mathrm{~h}$ after hCG injection with the majority of follicles ovulating at 14 to $15 \mathrm{~h}$ after hCG, although a few $(<10 \%)$ ovulated earlier or later. An average of 5 follicles per ovary underwent ovulation with a range of 3-7 ovulated follicles from a given ovary.

During the $14 \mathrm{~h}$ preovulatory period, very little surface change was seen until about $4 \mathrm{~h}$ before expected ovulation. Numerous large, rounded follicles were seen on the whole ovary, and apical regions of follicles were characterized by a rosette pattern of surface epithelial cells with few noticeable intercellular spaces (Pl. 1, Fig. 1).

Beginning at about $10 \mathrm{~h}$ after hCG injection ( $4 \mathrm{~h}$ before expected ovulation) and continuing until as late as $16 \mathrm{~h}$ after hCG ( $2 \mathrm{~h}$ after expected ovulation), a series of surface changes resulting in rupture and ovulation was detected. Folds or wrinkles were seen at the bases of follicles, and surface epithelial cells at the apex were folded into wrinkles bordering a slight bulge of the basal lamina where a few widely separated surface epithelial cells appeared to be left 'floating' on the tiny 'stigma' (Pl. 1, Fig. 2). A small bleb (possibly representing a viscous fluid) appeared at the apex over the raised stigma area which subsequently collapsed leaving a slightly depressed central area from which an underlying protrusion of cells lifted the still intact basal

\section{PLATE 1}

Fig. 1. Large preovulatory follicle $2 \mathrm{~h}$ after hCG showing the typical rosette pattern of the surface epithelial cells (arrow) at the apex. $\times 160$.

Fig. 2. Preovulatory follicle $12 \mathrm{~h}$ after hCG showing a small stigma (arrow) with some isolated 'floating' surface epithelial cells on the basal lamina (BL). $\times 320$.

\section{PLATE 2}

Fig. 3. Apex of follicle $12 \mathrm{~h}$ after hCG with a protrusion of cells lifting the basal lamina from a depressed area at the apex (arrow). A few granulosa cells (GrC) are seen. $\times 640$.

Fig. 4. Apex of a follicle $12 \mathrm{~h}$ after hCG with a small cluster of granulosa cells exuding from the slightly depressed rupture area. $\times 640$. 
PLATE 1
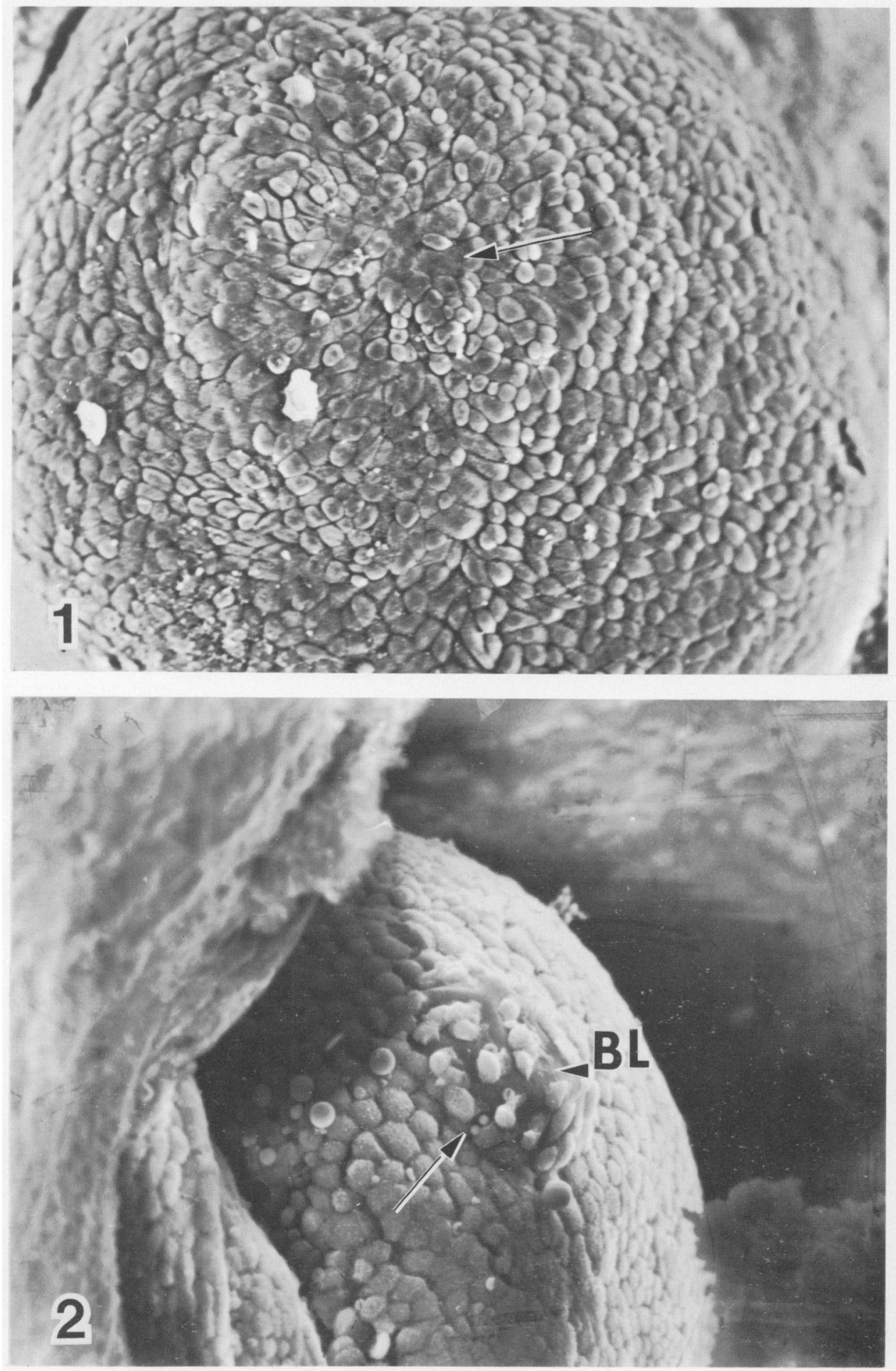

(Facing p. 22) 
PLATE 2
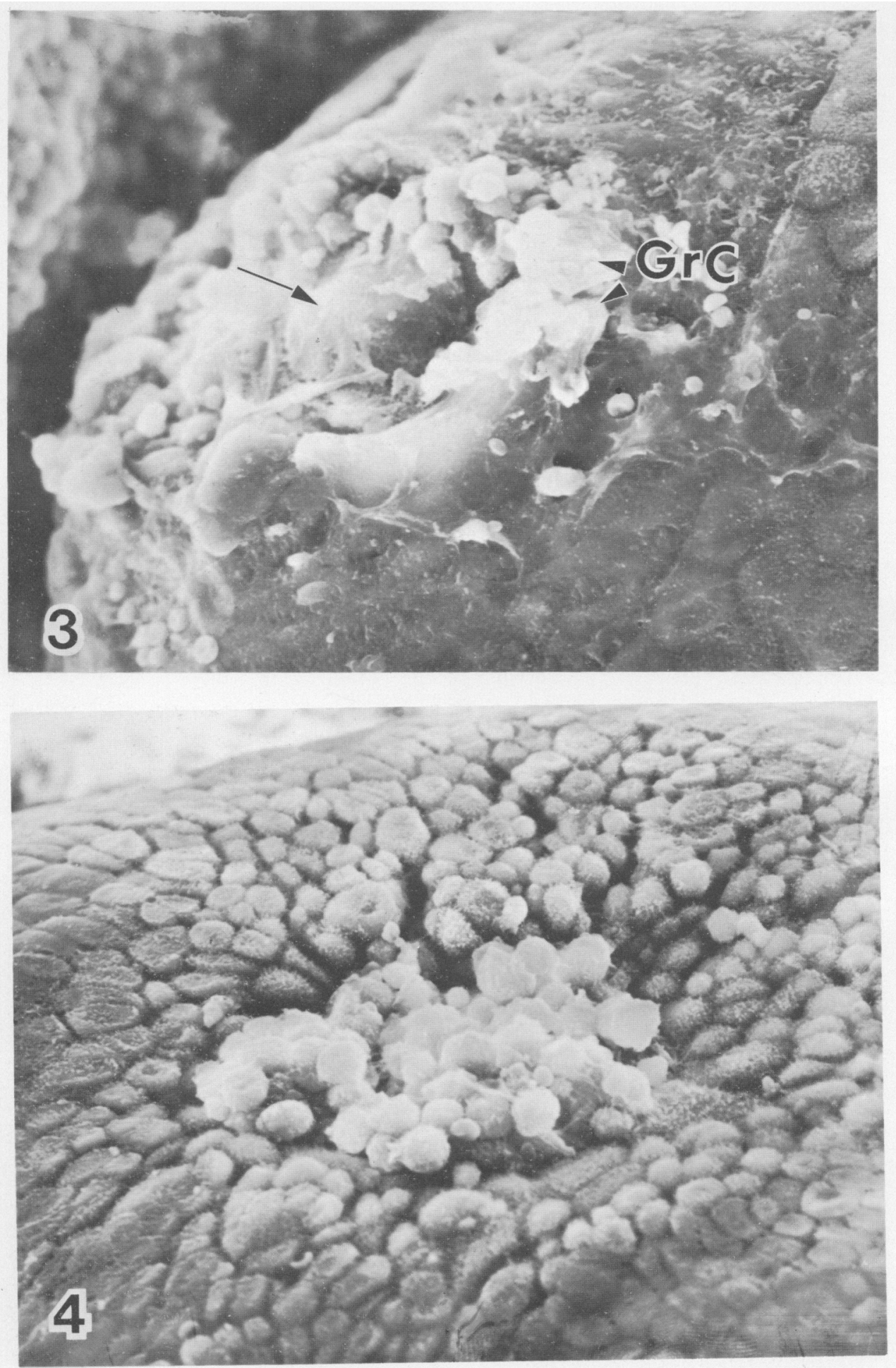
PLATE 3
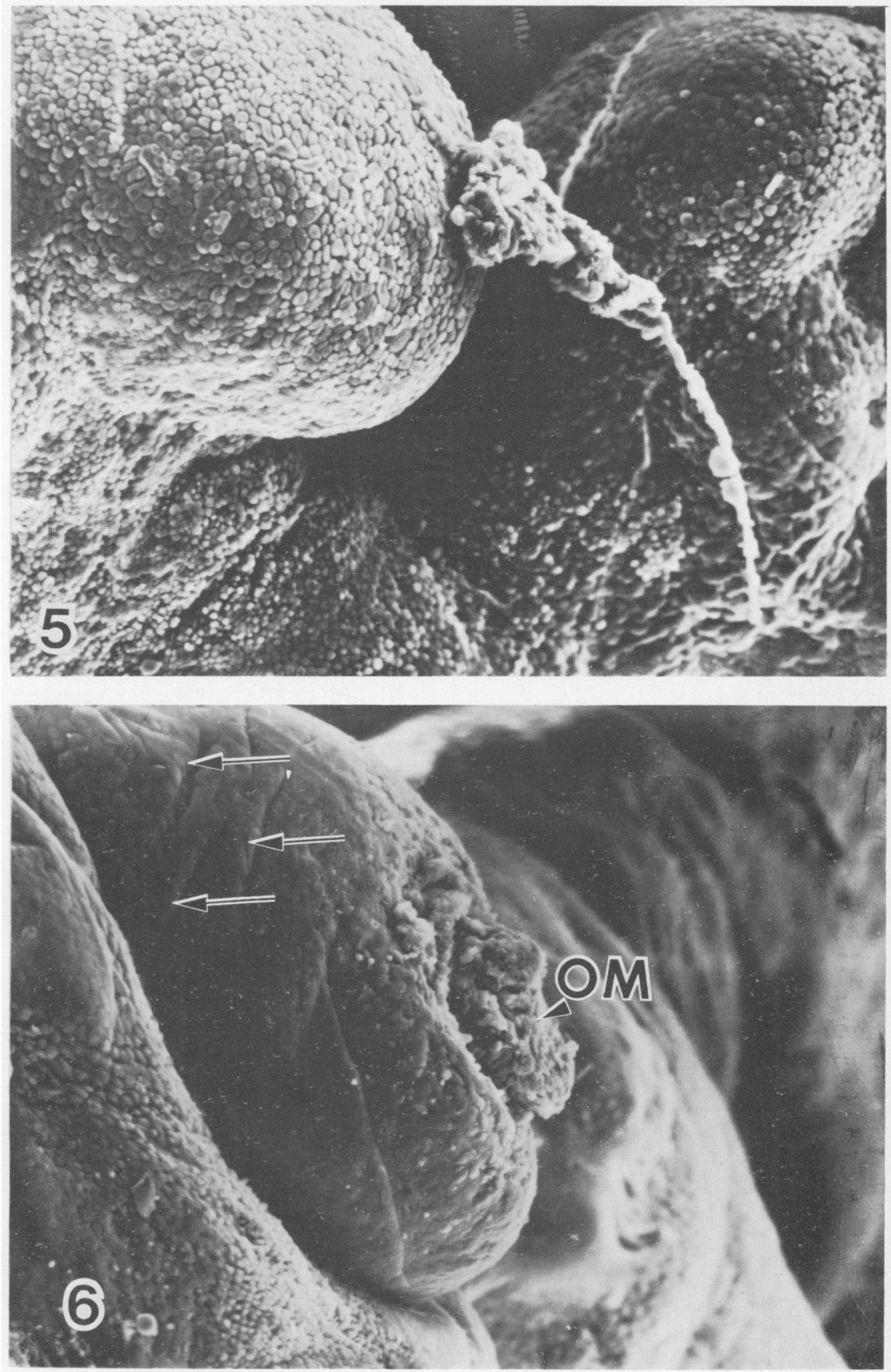
PLATE 4
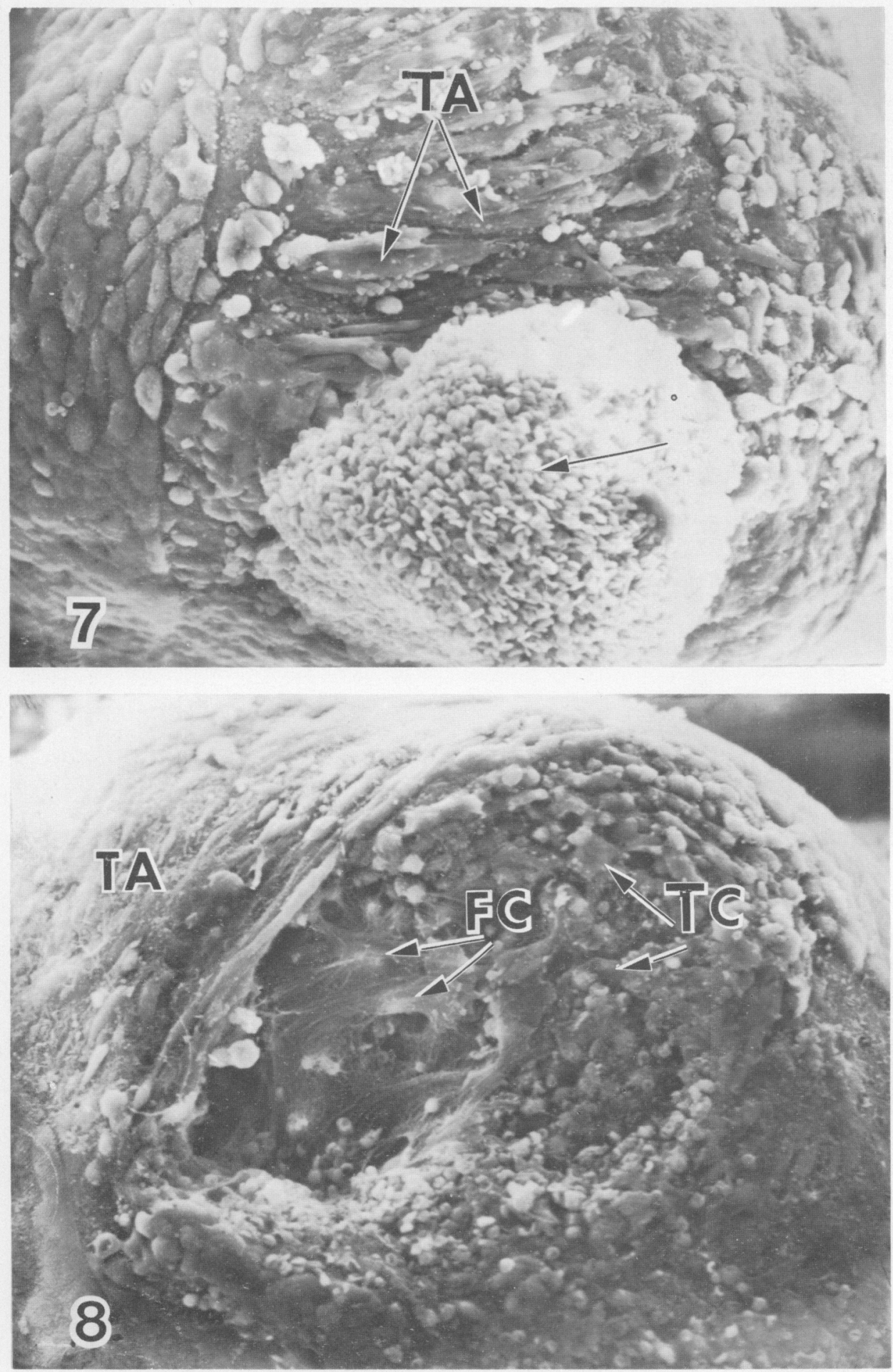
lamina (Pl. 2, Fig. 3). Then a small cluster of granulosa cells appeared (PI. 2, Fig. 4) and continued to develop into an upright column as if propelled by an underlying force (PI. 3, Fig. 5). This was followed by the expulsion of the oocyte with its surrounding mass from the apex of a wrinkled follicle (Pl. 3, Fig. 6).

The surface immediately surrounding the oocyte mass was denuded of epithelial cells, and the exposed tunica albuginea was drawn into parallel rows suggesting an underlying contractile force. Large masses of red blood cells, possibly representing blood clots, were occasionally seen at the rupture site (Pl. 4, Fig. 7). The post-ovulatory follicle displayed a cavernous rupture site in which red blood cells, tunica albuginea cells, and fibroblast-like cells, possibly representing smooth muscle, were seen (Pl. 4, Fig. 8).

\section{Discussion}

While the overall sequence of ovulation described above correlates well with other descriptions of mammalian ovulation, there were some differences. First, stigma formation in the hamster is unremarkable and difficult to detect. This is in contrast to the rabbit in which a large, protruding stigma is observed (Blandau, 1967); formation of a prominent stigma has also been reported in mouse, rat, guinea-pig and man (Motta \& Van Blerkom, 1975). Moreover, stigma formation in these animals has been attributed to degeneration and sloughing of the surface epithelial cells (see Espey, 1967; Byskov, 1969; Motta et al., 1971; Motta \& Van Blerkom, 1975), a condition we have been unable to detect in the hamster. Microfilaments have been observed in the surface epithelial cells of the hamster (Pendergrass \& Talbot, 1979), and these may act to draw the cells into folds as contractions at the base of the follicle create intrafollicular pressure which pushes the basal lamina outward to form the small stigma, i.e. stigma formation in the hamster may be caused by the eruption of the oocyte rather than by earlier enzymic digestion of the surface cells.

Another way that hamster ovulation differs from that reported in other mammals is in the ovulatory process itself. Ovulation has mostly been described as an oozing process following rupture of a large stigma (see Doyle, 1951; Blandau, 1967; Motta \& Van Blerkom, 1975); however, we have found the early portion of the process to resemble an eruption with a detectable column of cells standing away from the surface of the follicle. This suggests an underlying propelling force rather than an oozing process which should result in a clump of cells adhering to the side of the follicle; however, our evidence is insufficient to determine whether later stages of ovulation involve an oozing process. Spurting follicles have been reported during natural ovulation in the rat (Blandau, 1955). A possible explanation for the difference is that, in animals in which a large stigma is formed, rupture of the stigma results in an opening of sufficient size to allow passage of the oocyte. In the hamster, however, an ejecting force is needed to expel the oocyte through the small stigma. Such a force is suggested by the large wrinkles seen at the base of the follicle as stigma formation begins and throughout ovulation. McReynolds, Siraki,

\section{PLATE 3}

Fig. 5. Follicle $15 \mathrm{~h}$ after hCG with a column of granulosa and tunica cells standing away from the follicle surface. $\times 160$.

Fig. 6. Ovulating follicle $16 \mathrm{~h}$ after hCG with exposed oocyte mass (OM) and large wrinkles at the base (arrows). $\times 160$.

PLATE 4

Fig. 7. Rupture site $15 \mathrm{~h}$ after hCG with a large clump of red blood cells (arrow) and the exposed tunica albuginea (TA) which is folded. $\times 640$.

Fig. 8. Cavernous rupture site $14 \mathrm{~h}$ after hCG showing fibroblast-like cells (FC) and thecal cells (TC) bordered by a folded tunica albuginea (TA). $\times 320$. 
Bramson \& Polloch (1973) and Pendergrass \& Talbot (1979) have reported smooth muscle-like and smooth muscle cells in the base and apex, respectively, of the hamster follicle as seen with the transmission electron microscope, and the contraction of these cells could produce the ejecting force needed to effect ovulation.

In considering how our results help in the interpretation of theories of ovulation, we find at least partial support for all four proposed mechanisms. Build-up of intrafollicular pressure is supported by the leakage of a fluid-like bleb and the ensuing spurt-like column of cells seen early in ovulation. An inflammatory response resulting in ruptured intrafollicular capillaries is suggested by the mass of red blood cells occasionally seen at the rupture site, although the force of oocyte expulsion could also cause ruptured blood vessels. Smooth muscle and microfilamentous contractions are suggested by the large wrinkles observed at the base of the follicle, by the folds of surface epithelial cells surrounding the stigma, and by the parallel rows of tunica albuginea bordering the rupture site. Enzymic digestion is suggested by the widely separated epithelial cells at the stigma, although necrosis does not seem to be involved. Studies utilizing scanning electron microscopy coupled with subsequent transmission electron microscopy of the same follicles are currently underway and should provide a more direct correlation of surface events with underlying ultrastructural changes, thereby giving additional information about the mechanisms involved in hamster ovulation.

This project was supported by NIH Grant HD11008-01, by the Department of Anatomy at Wright State University, and by research funds from Texas Woman's University. Part of this work was undertaken as partial fulfilment of the requirements for the M.S. degree from Texas Woman's University by M.R.

\section{References}

Anderson, E., Lee, G., Le Tourneau, R., Albertini, D. \& Meller, S. (1976) Cytological observations of ovarian epithelium in mammals during the reproductive cycle. J. Morph. 150, 135-166.

Baccarini, I. (1975) Scanning and transmission electron microscopy of the "germinal epithelium" of the human ovary. Anat. Rec. 181, 305-306.

Bjersing, L. \& Cajander, S. (1974) Ovulation and the mechanism of follicle rupture. II. Scanning electron microscopy of rabbit germinal epithelium prior to induced ovulation. Cell. Tiss. Res. 149, 301-312.

Bjersing, L. \& Cajander, S. (1975) Ovulation and the role of ovarian surface epithelium. Experientia 31, $605-608$.

Blandau, R. (1955) Ovulation in the living albino rat. Fert. Steril. 6, 391-404.

Blandau, J. (1967) Anatomy of ovulation. Clin. Obstet. Gynec. 10, 347-360.

Byskov, A. (1969) Ultrastructural studies on the preovulatory follicle in the mouse ovary. Z. Zellforsch. mikrosk. Anat. 100, 285-299.

Cajander, S. (1976) Structural alterations of rabbit ovarian follicles after mating with special reference to the overlying surface epithelium. Cell Tiss. Res. 173, 437-449.

Cherney, D., Motta, F. \& Didio, L. (1973) Ovarian villi in rabbits studied with light, scanning, and transmission electron microscopy. J. Microscopie 17, 3740 .
Doyle, J. (1951) Exploratory culdotomy for observations of tuboovarian physiology at ovulation time. Fert. Steril. 2, 474-486.

Espey, L. (1967) Ultrastructure of the apex of the rabbit Graafian follicle during the ovulatory process. Endocrinology 81, 267-276.

Karnovsky, M. (1965) A formaldehyde-glutaraldehyde fixation of high osmolarity for use in electron microscopy. J. Cell Biol. 27, 137.

McReynolds, H., Siraki, C., Bramson, P. \& Polloch, R. (1973) Smooth muscle-like cells in ovaries of the hamster and gerbil. Z. Zellforsch. mikrosk. Anat. 140, 1-8.

Motta, P. \& Van Blerkom, J. (1975) A scanning electron microscope study of the luteo-follicular complex. II. Events leading to ovulation. Am. J. Anat. 143, 241264.

Motta, P., Cherney, D. \& Didio, L. (1971) Scanning and transmission electron microscopy of the ovarian surface in mammals with special reference to ovulation. J. submicrosc. Cytol. 3, 85-100.

Nilsson, O. \& Munshi, S. (1973) Scanning electron microscopy of mouse follicles at ovulation. J. submicrosc. Cytol. 5, 1-6.

Pendergrass, P. \& Talbot, P. (1979) The distribution of contractile cells in the apex of the preovulatory hamster follicle. Biol. Reprod. 20, 205-213.

Received 31 July 1979 